\title{
Flake scar patterns of Japanese tanged points: toward an understanding of technological variability during the Incipient Jomon
}

\author{
Kenji NAGAI ${ }^{1 *}$ \\ ${ }^{1}$ Graduate School of Frontier Sciences, The University of Tokyo, 7-3-1 Hongo, Bunkyo-ku, Tokyo, 113-0033 Japan
}

Received 11 December 2006; accepted 24 April 2007

\begin{abstract}
Tanged points have long been considered an important proxy for cultural variability during the Incipient Jomon period of Japan. Historically, interpretations of cultural variability based on tanged points have relied entirely on studies of tang morphology. However, little attention has been paid to technological variation, which is a stronger indicator of culturally learned behavior than are morphological typologies. This paper describes ongoing research of flake scar orientation on tanged points produced by the oblique parallel pressure flaking (OPPF) technique from the Incipient Jomon. The results indicate that there is a highly significant, geographically patterned technological variation of such points. OPPF points from the south of Japan are exclusively flaked from the upper right to the lower left (URLL), while points from the north are almost always flaked from the upper left to the lower right (ULLR). Experimental research by the author and others suggests that this variation may indicate the adoption of different pressure flaking techniques in these two regions. If one considers the diversity of the flake scar patterns as an indicator of isochrestic variation in the Incipient Jomon period, the people of both regions appear to have had different culturally conditioned techniques of pressure flaking. This suggests that they did not adopt the same traditional rules concerning pressure flaking, nor did they have identical cultural behavior.
\end{abstract}

Key words: Incipient Jomon, tanged points, pressure flaking techniques, oblique parallel pressure flaking (OPPF), flake scar orientation

\section{Introduction}

The purpose of this paper is to describe the technological variation of tanged points in the Incipient Jomon period of Japan. Specific attention is paid to the relationship between diagonal flake scar patterns and their geographical distribution, which are the result, to some extent, of differences in pressure flake removal techniques. I further illustrate how such analyses can contribute to the interpretation of the particular idiosyncratic behaviors of local groups in the Incipient Jomon. The interpretations presented here are based on both experimental and archaeological studies.

While pioneering studies by Japanese archaeologists have detailed a highly patterned type of tanged point in the Incipient Jomon, there have been no comprehensive studies of the variation in tanged point production techniques, or of the dynamics of their fabrication, use, and abandonment. This is partially due to the fact that, until recently, Incipient Jomon archaeology has focused primarily upon the typology of the style of the base of the points. Tanged points of the so-called Tachikawa, Yanagimata, Kosegasawa, Hanamiyama, and other types are examples of this classic typology (e.g. Serizawa, 1966; Kurishima, 1984; Shiraishi, 1988). Recent studies (Kimura, 1995; Nagai, 2006) suggest that these clas-

* Corresponding author. e-mail: tyuyou@gk9.so-net.ne.jp phone: +81-3-5841-3793; fax: +81-3-5841-3793

Published online 30 June 2007

in J-STAGE (www.jstage.jst.go.jp) DOI: 10.1537/ase.061211 sical types are based on morphological style and cannot indicate the behavioral and/or 'cultural' meaning of the type. Kimura (1995) has shown, for instance, that some classical types of microcores in Hokkaido were produced by variable microblade production techniques, as well as variable dynamics of fabrication, use, and abandonment. Nagai (2006) argued that the patterning of Japanese tanged point pressure flaking techniques is isochrestic (sensu Sackett 1990) in nature. This experimental research by the present author suggested that pressure flaking techniques are a stronger indicator of culturally learned behavior than are morphological typologies.

Additionally, the lack of detailed flake scar and lithic debitage analyses have compromised a comprehensive understanding of the technological variability of the lithic assemblages. Experimental analysis of flake scar patterns plays an important role in contributing to our understanding of the basic features of the technology. The holding position of the biface and the direction of the applied force were socially learned behaviors which resulted in recognizable isochrestic 'styles'. Taken together, experimental analysis permits an understanding of the sequential physical actions and decision-making strategies by which lithic raw material was transformed into cultural objects.

\section{The Characteristics of Diagonal Tanged Points}

Diagonal tanged points were made in early prehistoric Japan during the Incipient Jomon period (c. 13000-9500 
RCYBP). The oblique parallel pressure flaking (OPPF) technique, common in the Incipient Jomon (Kobayashi, 1961; Takahashi, 1983; Nagai, 2006), leaves a pleasing, rippled surface covered with regular flake scars, with varied patterns. Figure 1 illustrates tanged points of the so-called Tachikawa and Yanagimata types. The sophisticated nature of the pressure flaking applied to these tools may indicate that it had a decorative purpose. OPPF tanged points were made from various local raw materials, such as obsidian, chert, andesite, and siliceous shale.

According to Mituishi, 1165 tanged points have been retrieved from 978 sites in southern Honshu and Shikoku (Mituishi, 2005: Table 1). In addition, the author has recorded 327 sites with tanged points in Shikoku (Nagai, 2000: Table 1), Hokkaido, northern Honshu, and Kyushu. More than 1500 tanged points have been documented in Japan as a whole. This suggests the possibility that we can analyze lithic technology by using a large number of tanged points retrieved from a wide geographical area. This study has incorporated experimental data from bifacial flake scar pattern analysis (e.g. Hirth et al., 2003; Nagai, 2006) to the Incipient Jomon archaeological data.

\section{Flake Scar Patterns}

So far, 305 OPPF tanged points have been recorded from 204 sites in Japan. The aggregate numbers of both sites and OPPF tanged points in each prefecture are as follows: Okayama 4 sites/6 points (hereafter abbreviated as $4 / 6$ ), Fukuoka (1/1), Ehime (7/7), Kagawa (2/2), Tokushima (2/2), Kochi (1/1), Tottori (2/2), Shimane (1/1), Hiroshima (5/5), Hyogo (11/11), Osaka (22/30), Kyoto (6/6), Shiga (6/6), Nara (9/10), Wakayama (3/3), Mie (12/15), Aichi (20/25), Gifu (56/63), Fukui (3/5), Toyama (1/1), Nagano (9/11), Shizuoka (1/1), Yamagata (1/1), and Hokkaido (19/90).

Throughout Japan, variation can be found in the quality and form of pressure flaking on tanged points. A repeated characteristic of pressure flaking techniques in southern Japan during the Incipient Jomon period is the tendency for diagonal flake scar patterns on the biface to be oriented from upper-right to lower-left (URLL) (Figure 1, left). The right-oriented scars are visible on both faces of the biface. On the other hand, a repeated characteristic of pressure flaking techniques in northern Japan in the same period is the tendency for them to be oriented from upper-left to lowerright (ULLR) (Figure 1, right). The left-oriented scars are visible on both faces of the biface. Of the 305 OPFF tanged points 215 from the south are URLL-orientated, while 90 from the north are ULLR-orientated. The difference in flake scar orientations between URLL-OPPF and ULLR-OPPF suggests the use of a consistent pressure flaking technique over a wide geographical area during the Incipient Jomon period.

According to Hirth et al. (2003: p. 148), there are three separate experimental pressure flaking techniques that can produce these two flake scar orientations. These are the Ishi, Titmus, and Crabtree/Tixier techniques. Two of these techniques, the Titmus and the Crabtree/Tixier, produce URLL diagonally oriented flake scar patterns similar to those found on bifaces in southern areas of Japan (i.e. Honshu, Shikoku, and Kyushu). The Ishi pressure flaking technique produces lower-right to upper-left diagonally oriented flake scar patterns similar to those found on bifaces in northern Japan (i.e. Hokkaido). This indicates the possibility that different pressure flaking techniques were adopted in each geographical area in prehistoric Japan (Figure 2).

\section{Discussion}

The most significant difference between Japanese tanged points is the flake scar orientation on their bifaces. Kurishima (1984) and others have suggested that these tanged
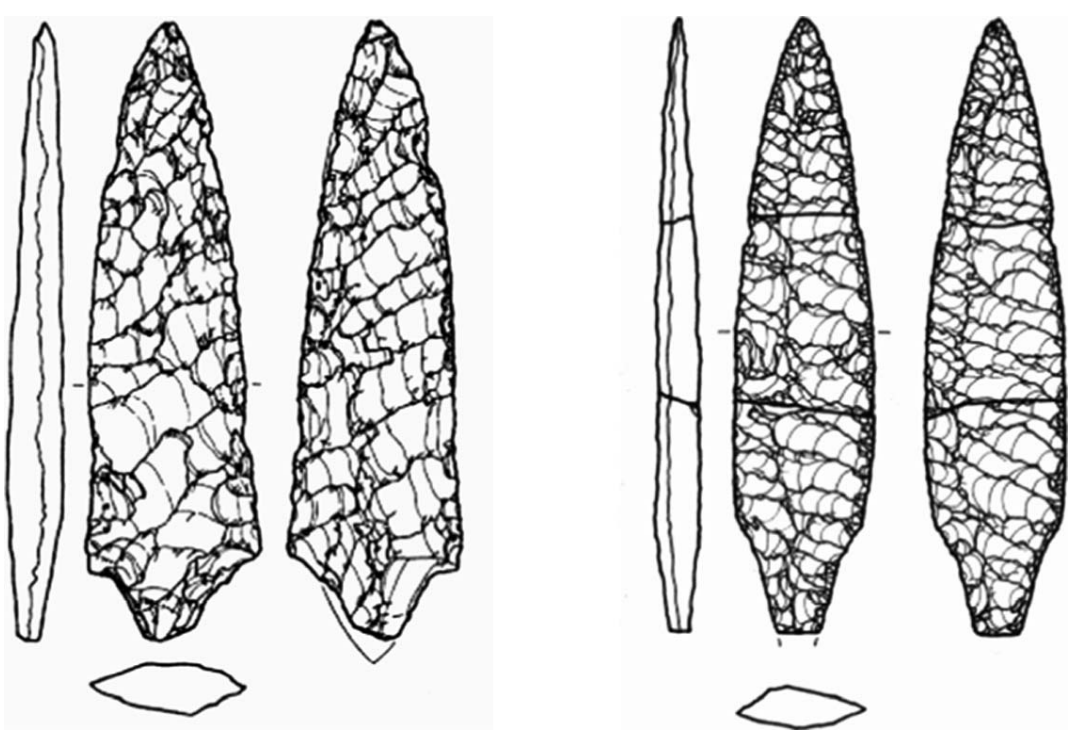

Figure 1. Oblique parallel pressure flaking (OPPF) of Incipient Jomon tanged points (modified and redrawn from Nagai, 2006: 13; Naganuma et al., 2001: 178). Left set of figures: URLL (upper-right to lower-left) Inoken Site, Okayama Prefecture. Right set of figures: ULLR (upper-left to lower-right) Kamishirataki 2 Site, Hokkaido. 


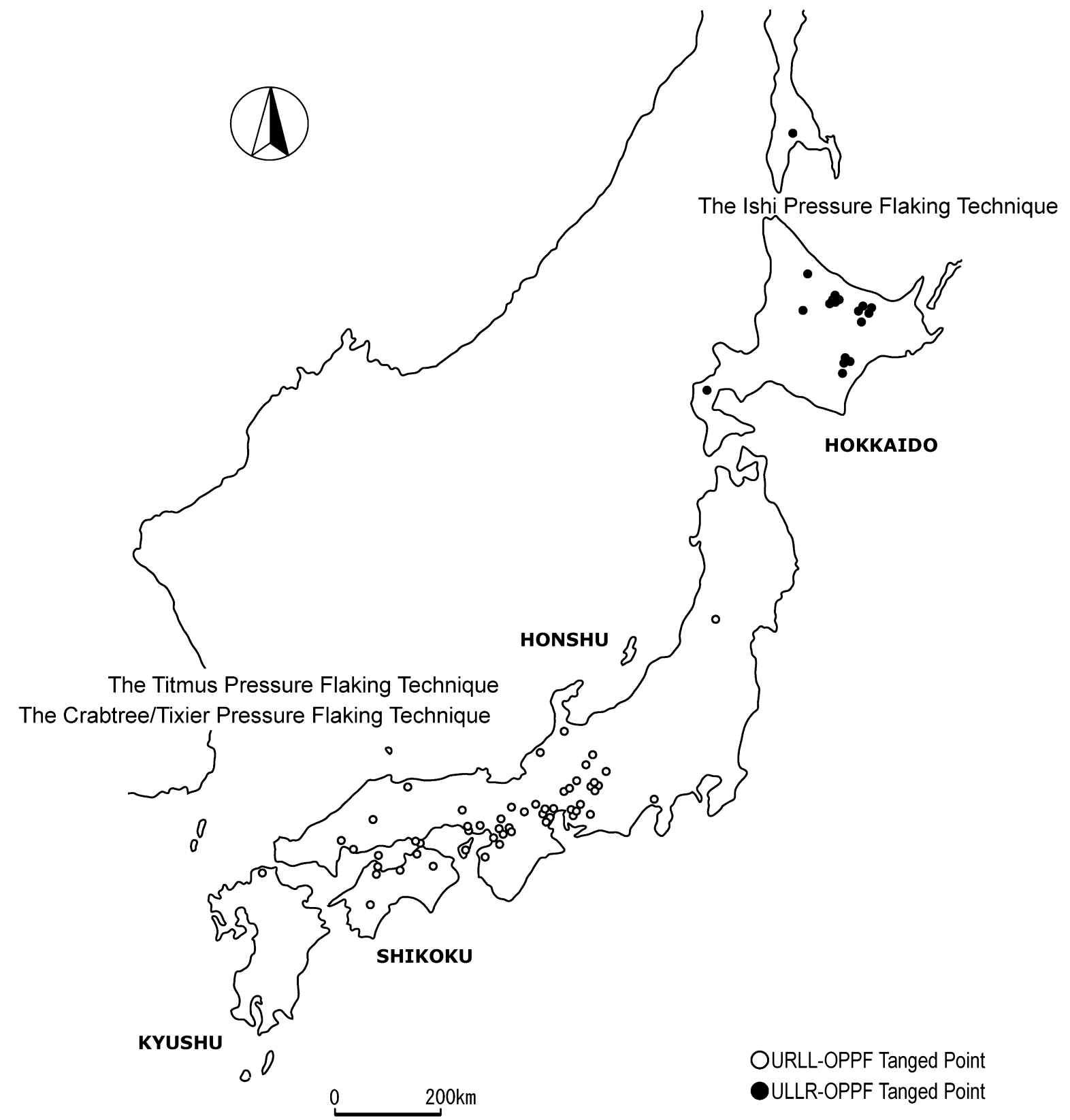

Figure 2. Geographical distribution of diagonal flake scar patterns.

points spread mainly from north to south, in other words, from Hokkaido to Honshu or from Shikoku to Kyushu. Kurishima $(1984,1991)$ based this model of diffusion largely on a morphological classification of the tanged points. Similarly, Shiraishi has proposed cultural-geographical distributions based on tang morphologies (Shiraishi, 1988: p. 70, Fig. 2; Shiraishi, 2001). However, the analysis presented here does not support these hypotheses. It is important to understand the variation found in pressure flaking patterns on bifaces and also to understand the technical processes, which suggest unconscious preferences in technology. It is for these reasons that different pressure flaking techniques will produce different flake scar orientations. If one considers the diversity of flake scar patterns as proxies for culturally conditioned physical actions in the Incipient Jomon period, populations in both the south and north of Japan appear to have had different cultural preferences in pressure flaking techniques. This is suggested by the fact that both populations do not appear to have ever adopted the same traditional rules concerning pressure flaking, nor did they have identical cultural behavior. In other words, it suggests the possibility that two distinct cultures appeared during the Incipient Jomon period in the south and north of Japan.

Furthermore, it is important to note that ULLR-OPPF tanged points have been retrieved from the Ogonjki V site in southern Sakhalin, Russia (Vasilevski, 2005). This ULLR- 
OPPF pattern was very common during the Incipient Jomon period throughout Hokkaido. These facts enhance the possibility that both Hokkaido and Sakhalin's prehistoric cultures shared identical pressure flaking technical processes.

\section{Acknowledgments}

The author thanks Yoshihiro Nishiaki (University of Tokyo), Gilbert Tostevin (University of Minnesota), and Ian Wallace (Stony Brook University) for providing helpful comments on an earlier draft of this paper. The author also wishes to thank Robert W. Love, founder of the Michigan Flintknappers, for his help in the preparation of this paper. Any mistakes or omissions are my fault alone.

\section{References}

Hirth K., Flenniken J., Titmus G., and Tixier J. (2003) Alternative techniques for producing Mesoamerican-style pressure flaking patterns on obsidian bifaces. In: Hirth K.G. (ed.), Mesoamerican Lithic Technology: Experimentation and Interpretation. The University of Utah Press, Salt Lake City, pp. 147-152.

Kimura H. (1995) Obsidian, people and technology. Hokkaido Kokogaku (Journal of the Hokkaido Archaeological Society), 31: 3-64 (in Japanese).

Kobayashi T. (1961) Tanged points. Rekishi Kyoiku (Historical Education), 8: 49-50 (in Japanese).

Kurishima Y. (1984) Style and diffusion of stemmed points. Sundai Shigaku (Sundai Historical Review), 62: 50-82 (in Japanese).

Kurishima Y. (1991) Routes of Japanese stemmed points. Tonegawa, 12: 6-11 (in Japanese).

Mituishi N. (2005) A Study of the Incipient Jomon Cultures in the Southern Part of Honshu: Toward an Understanding of the Formation Process of Jomon Stone Tool Assemblages (Honshu Seihanbu ni okeru Jomon Jidai Sosoki no Yoso:
Jomon-teki Shuryogu Kosei no Seiritsu Katei ni Kansuru Kenkyu). Meishin-sha, Nara (in Japanese).

Nagai K. (2000) The tanged point collected from Agataoike site in Ehime prefecture. Kyusekki Kokogaku (Paleolithic Archaeology), 59: 81-86 (in Japanese).

Nagai K. (2006) Replicating the oblique parallel pressure flaking (OPPF). Kokogaku Journal (The Archaeological Journal), 547: 5-10 (in Japanese).

Naganuma T., Suzuki H., Naoe Y., and Kosida M. (2001) The Shirataki Sites II, Part 2: The Kamishirataki 2, Kamishirataki 6 and Kitashibetsu 4 Sites (Shirataki Iseki-gun II, Dai 2 Bunsatu, Kamishirataki 2 Iseki, Kamishirataki 6 Iseki, Kitashibetsu 4 Iseki). Hokkaido Maizo Bunkazai Center (Archaeological Center of Hokkaido), Hokkaido (in Japanese).

Sackett J.R. (1990) Style and ethnicity in archaeology: the case for isochrestism. In: Conkey M. and Hastorf C. (eds.), The Use of Style in Archaeology. Cambridge University Press, Cambridge, pp. 32-43.

Serizawa T. (1966) A study of the tanged points excavated from Nakabayashi site in Niigata prefecture. Nihon Bunka Kenkyujo Kenkyu Hokoku (Reports of the Research Institute for Japanese Culture), 2: 1-67 (in Japanese).

Shiraishi H. (1988) An issue concerning the origin of the Jomon culture: a suggestion, with special reference to the understanding of tanged points. Kanagawa Koko, 24: 65-80 (in Japanese).

Shiraishi H. (2001) Studies of bifaces: from the Paleolithic age to the Incipient Jomon period (Ishiyari no Kenkyu: Kyusekki Jidai kara Jomon Jidai Shoto-ki ni kakete). Musee, Tokyo (in Japanese).

Takahashi A. (1983) A study on the tanged points with oblique parallel flaking. In: Aso M. (ed.), Ningen, iseki, ibutsu (People, Site and Artifact). Archaeological Issue 1, Tokyo, pp. 147-162 (in Japanese).

Vasilevski A.A. (2005) Central and Eastern Asia. In: Derevianko A.P. (ed.), The Middle to Upper Paleolithic Transition in Eurasia: Hypotheses and Facts. Institute of Archaeology and Ethnography Press, Novosibirsk, pp. 427-445. 